\title{
Trombosis del seno cavernoso derecho secundaria a rinosinusitis esfenoidal. Reporte de caso
}

\author{
Right cavernous sinus thrombosis secondary to sphenoidal rhinosinusitis. \\ Case report
}

\author{
Nicolás Pons $\mathrm{C}^{1}$, Rodrigo Pacheco Z², Álvaro Pacheco T ${ }^{3}$, Patricio Tabilo $\mathrm{C}^{3}$, Constanza Valdés $\mathrm{P}^{1}$.
}

\begin{abstract}
RESUMEN
La rinosinusitis bacteriana aguda es la infección de la mucosa nasal y de senos paranasales, que se manifiesta con congestión nasal, rinorrea purulenta y fiebre, de curso generalmente autolimitado. La trombosis del seno cavernoso (TSC) es una complicación poco frecuente, que se asocia a compromiso del seno esfenoidal y etmoidal, manifestándose clínicamente con cefalea, fiebre, alteración de pares craneanos y síntomas oculares. Ante su sospecha el estudio imagenológico es fundamental. En estos exámenes se debe buscar un defecto de llene en el seno cavernoso comprometido. El tratamiento debe iniciarse de forma precoz y contempla: antibioticoterapia, drenaje quirúrgico del seno afectado y anticoagulación. Se presenta a un paciente pediátrico masculino con TSC derecha posterior a una rinosinusitis esfenoidal no tratada, que respondió favorablemente al tratamiento. Se describe la clínica y manejo de esta patología, que presenta alta morbimortalidad, y que puede disminuirse considerablemente con un tratamiento precoz y agresivo.
\end{abstract}

Palabras clave: Enfermedad de los senos paranasales, sinusitis, sinusitis esfenoidal, sinusitis complicada, trombosis del seno cavernoso.

\begin{abstract}
Acute bacterial rhinosinusitis is the infection of the nasal and paranasal mucous membrane, with symptoms such as nasal congestion, purulent rhinorrhea and fever, usually self-limiting. Cavernous sinus thrombosis (CST) is a rare complication, which is associated with sphenoid and ethmoid sinus involvement, clinically manifest with headache, fever, cranial nerve involvement and ocular symptoms. When suspected, imaging studies will confirm the clinical impression. They will show abnormal flow parameters in the compromised cavernous sinus. The treatment has to start as soon as possible and consists in broad spectrum intravenous antibiotics, surgical drainage of the site of the
\end{abstract}

\footnotetext{
Servicio de Otorrinolaringología, Hospital del Salvador, Santiago, Chile.

Escuela de Medicina, Universidad de la Frontera, Temuco, Chile.

3 Servicio Otorrinlaringología, Hospital Dr. Luis Calvo Mackenna, Santiago, Chile.
}

Los autores declaran no tener conflictos de interés.

Recibido el 11 de diciembre, 2018. Aceptado el 3 de febrero, 2019. 
infection and anticoagulation. We present a patient with a right CST secondary to a nontreated sphenoidal sinusitis, that responded favorably to treatment. The clinical and management of this pathology is described, which presents a high morbidity and mortality that can be reduced considerably with an early and aggressive treatment.

Key words: Paranasal sinus disease, sinusitis, sphenoid sinusitis, complicated sinusitis, cavernous sinus thrombosis.

\section{INTRODUCCIÓN}

La rinosinusitis es la inflamación de la mucosa nasal y de cavidades paranasales (CPN) ${ }^{1}$. Es una enfermedad común, que afecta hasta $14 \%$ de los adultos, 030 millones de personas en Estados Unidos cada año ${ }^{2}$, representando hasta el $21 \%$ de las prescripciones de antibióticos en niños ${ }^{3,4}$. Se clasifica en aguda, subaguda, crónica y aguda recurrente según la duración de sus síntomas ${ }^{1}$. La rinosinusitis aguda (RSA) es la más frecuente, y su principal causa es infecciosa (viral o bacteriana). Se manifiesta clínicamente con congestión nasal, rinorrea purulenta, descarga posterior, cefalea, tos, dolor facial o dental y fiebre ${ }^{2,4}$.

Las CPN están limitadas por hueso que funciona como barrera $^{3}$. Los mecanismos por los cuales se producen las complicaciones son tromboflebitis de las venas comunicantes, destrucción ósea y defectos congénitos 0 adquiridos ${ }^{3-5}$. Las complicaciones de la RSA son principalmente infecciosas, estimándose en 3 casos por millón de habitantes ${ }^{2}$. Si bien, desde la incorporación del tratamiento antibiótico, son infrecuentes, aún suelen observarse principalmente en pacientes de sexo masculino y en especial, niños, adultos jóvenes e inmunocomprometidos ${ }^{2,3}$. Se clasifican en 2 tipos: intracraneales y orbitarias ${ }^{2}$. Es de suma importancia iniciar estudio con imágenes, como tomografía computarizada (TC) o resonancia magnética (RM), para su evaluación ${ }^{2}$, aunque no reemplazan el enfoque clínico ${ }^{4}$. Están indicadas en caso de duda diagnóstica, mala evolución clínica luego de 48 horas de iniciado el tratamiento médico y cuando se plantea cirugía ${ }^{4}$. La TC se utiliza como primer elemento diagnóstico, pero en ocasiones es mandatorio realizar una RM con gadolinio. Esta es necesaria cuando se sospecha compromiso intracraneal y en algunas condiciones especiales de pacientes con compromiso orbitario: edad de 7 años o más, sexo masculino, fracaso a tratamiento médico adecuado, cambios en el estado neurológico, opacificación del seno frontal en la TC, absceso subperióstico superior o lateral y necesidad de cirugía o drenaje quirúrgico del absces $0^{4}$.

Las complicaciones intracraneales se asocian a rinosinusitis frontal ${ }^{3}$, y se clasifican en: empiema epidural, empiema subdural, meningitis, cerebritis y absceso parenquimal ${ }^{4}$. Por otro lado, las complicaciones orbitarias se asocian principalmente a rinosinusitis etmoidal ${ }^{3}$, y son la complicación más común en RSA de niños, correspondiendo a $80 \%-90 \%$ del total ${ }^{3,4}$. Esto se debe a la proximidad del seno etmoidal con la pared orbitaria medial y la leve protección que ofrece la lámina papirácea, que predispone a que la infección se extienda hasta el ojo, donde el ligamento palpebral forma una barrera entre las estructuras intraorbitarias y los tejidos periorbitarios ${ }^{2,5}$.

Chandler creó un sistema de clasificación, que incluye 5 estadios: celulitis preseptal, celulitis orbitaria, absceso subperióstico, absceso orbitario y trombosis del seno cavernoso (TSC) ${ }^{4-6}$. Esta sistematización es importante a definir ante la presencia de una complicación, ya que tiene impacto a nivel de morbilidad y tratamiento ${ }^{2,6}$. El último grupo, que corresponde a la TSC es descrita por otros autores como parte de las complicaciones intracraneales, por lo que es materia de discusión ${ }^{3}$. Los hallazgos clínicos típicos, son edema y eritema periorbitario, proptosis, deterioro de la agudeza visual, limitación en la movilidad ocular, diplopía, visión borrosa, dolor ocular, quemosis y defectos en la pupila².

El siguiente caso se presenta por su interés pedagógico. Las complicaciones de RSA son poco frecuentes en la actualidad, en especial la TSC, por la incorporación de antibióticos. Esta es una entidad muy rara y potencialmente mortal, que requiere una alta sospecha clínica, además de un manejo precoz y agresivo para obtener resultados favorables, disminuyendo la morbimortalidad asociada. 
Este trabajo cuenta con asentimiento informado otorgado por el paciente, consentimiento informado firmado por su madre y con la autorización de la Dirección del Hospital Dr. Luis Calvo Mackenna para su publicación.

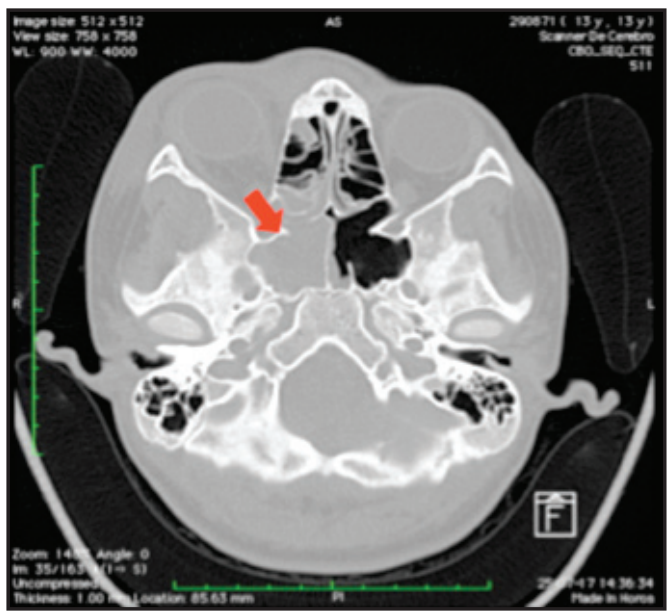

Figura 1. TC corte axial, ventana ósea. Se observa proptosis derecha y ocupación de seno esfenoidal y etmoidal posterior derecho por densidad partes blandas (flecha).

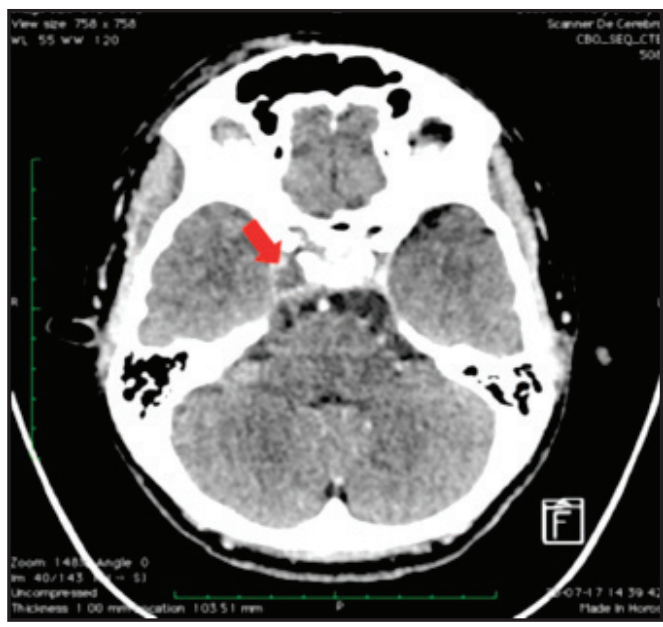

Figura 2. TC corte axial, ventana partes blandas. Se observa asimetría de senos cavernosos con aumento de volumen a derecha (flecha) con defecto de llene (hipodensidad) en su interior.

\section{CASO CLÍNICO}

Paciente de sexo masculino, 13 años de edad, presenta cuadro respiratorio alto de 2 semanas de evolución, al que se agregó cefalea hemicránea derecha persistente, aumento de volumen periocular derecho doloroso $7 / 10$ en escala visual análoga, acudiendo al Hospital Dr. Luis Calvo Mackenna al iniciar vómitos, fiebre y compromiso del estado general. Al ingreso se objetivó febril, vigil espontáneo, Glasgow Coma Scale 15, con aumento de volumen periorbitario derecho, blando, doloroso, con imposibilidad de realizar apertura ocular, asociado a rigidez de nuca. El estudio de laboratorio de ingreso mostró parámetros inflamatorios elevados por lo que se realizó una punción lumbar que resultó alterada, decidiendo hospitalizar en la unidad de tratamiento intermedio con diagnóstico de meningitis asociada a celulitis preseptal. Se inició tratamiento antibiótico triasociado por parte de infectología, que decidieron manejarlo como un absceso cerebral, con vancomicina, metronidazol y ceftriaxona. Evaluado por neurología: sin alteraciones del estado de conciencia ni de pares craneanos, pero con signos meníngeos presentes. Una vez hospitalizado se realizó una TC de cerebro que evidenció ocupación por un tejido con densidad de partes blandas del seno esfenoidal derecho (Figura 1) por lo que se realizó interconsulta a otorrinolaringología (ORL). En TC con ventana de partes blandas destacaba además asimetría de los senos cavernosos con aumento del tamaño del seno derecho y un defecto de llene en su interior (Figura 2).

Además, se observó trombosis de la vena oftálmica derecha. En evaluación por ORL se objetivó además del aumento de volumen periocular, una paresia del VI nervio craneano derecho, sin alteraciones evidentes de agudeza y campo visual, ni de la sensibilidad facial. Se diagnosticó una rinosinusitis esfenoidal derecha complicada con observación de TSC derecho, programándose cirugía endoscópica sinusal para realizar drenaje del seno, solicitando además una RM. Evaluado por oftalmología se objetiva: reflejo fotomotor presente bilateral, defecto pupilar aferente relativo negativo, fondo de ojo normal, diplopía presente. Durante la cirugía se realizó inicialmente una esfenoidotomía transnasal amplia con salida de abundante pus. 
Para facilitar las curaciones posteriores se realizó una antrostomía maxilar y etmoidectomía derecha (Figura 3).

Tras la cirugía evolucionó favorablemente. Se realizó una RM que informó extensa celulitis facial y orbitaria pre y postseptal derecha. Trombosis del seno cavernoso derecho y de las venas oftálmicas y faciales ipsilaterales. Aspecto de cambios inflamatorios con disminución de calibre de los segmentos intracavernosos de la arteria carótida interna derecha. Signos de paquimeningitis temporal anterior y del tentorio derecho (Figura 4a y 4b).

Se inició anticoagulación con heparina de bajo peso molecular a las 24 horas posoperatorias, sin incidentes, realizándose posteriormente el traslape a acenocumarol. Evolucionó favorablemente con disminución progresiva de parámetros inflamatorios. Cultivos intraoperatorios negativos. Completó 14 días de tratamiento con ceftriaxona (vancomicina y metronidazol fueron suspendidos tras la cirugía) y la paresia del VI nervio craneano se recuperó. La anticoagulación se mantuvo por 3 meses hasta tener un control con TC que evidenció permeabilización del seno cavernoso comprometido.

\section{DISCUSIÓN}

Los senos cavernosos consisten en un plexo venoso extradural rodeado de duramadre que se extiende desde el ápex orbitario y la fisura orbitaria superior a nivel anterior, hasta el cavum trigeminal y la duramadre a nivel posterior ${ }^{7}$. Están conectados a través de las venas intercavernosas anterior y posterior, tienen una relación íntima con la silla turca y a lo largo de su pared se encuentra la porción intracavernosa de la arteria carótida interna y los pares craneanos: oculomotor (III), troclear (IV), rama oftálmica y maxilar del trigémino (V1 y V2) y el abducens $(\mathrm{VI})^{7}$. La rinosinusitis esfenoidal aislada es poco común y potencialmente grave. Suele presentarse en adolescentes 0 preadolescentes con clínica poco específica, como síndrome febril asociado a cefalea retroorbitaria, frontal o temporal, lo que retrasa el diagnóstico y conduce a complicaciones severas, como la TSC ${ }^{7,8}$.

La TSC corresponde al $8 \%-16 \%$ de las complicaciones intracraneales ${ }^{9}$, sin embargo, su incidencia en asociación con RSA se desconoce. Si es vista como complicación orbitaria, Oxford

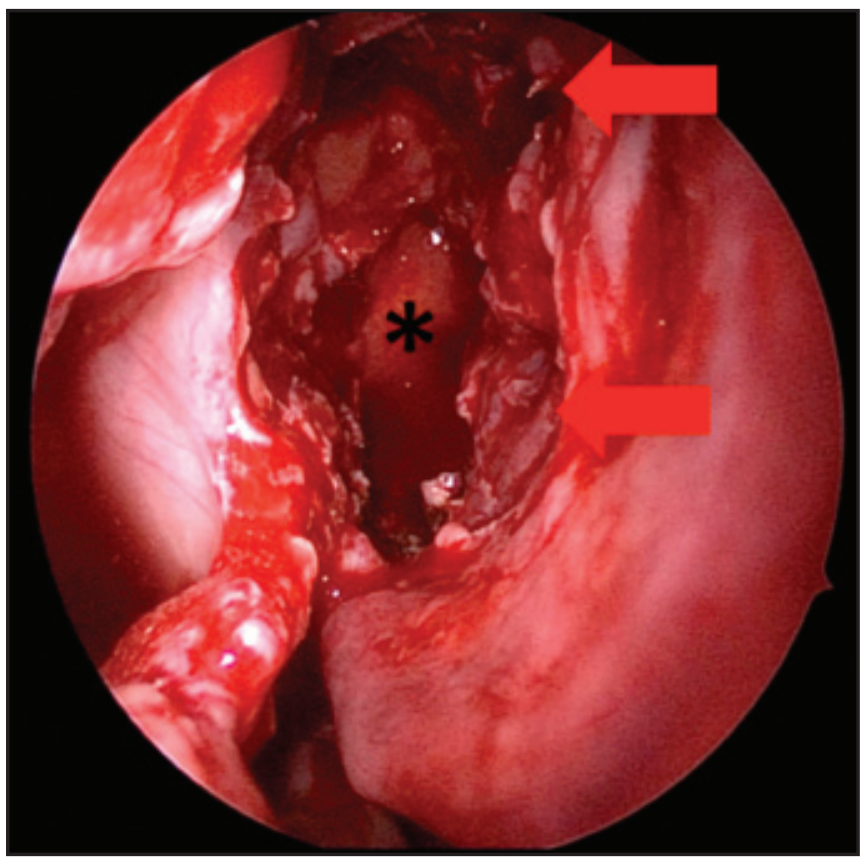

Figura 3. Visión endoscópica con óptica de $0^{\circ}$ de fosa nasal derecha al finalizar cirugía. Se observa la antrostomia maxilar $\left(^{*}\right)$, etmoidectomía y esfenoidotomía amplia (flecha superior e inferior, respectivamente). 

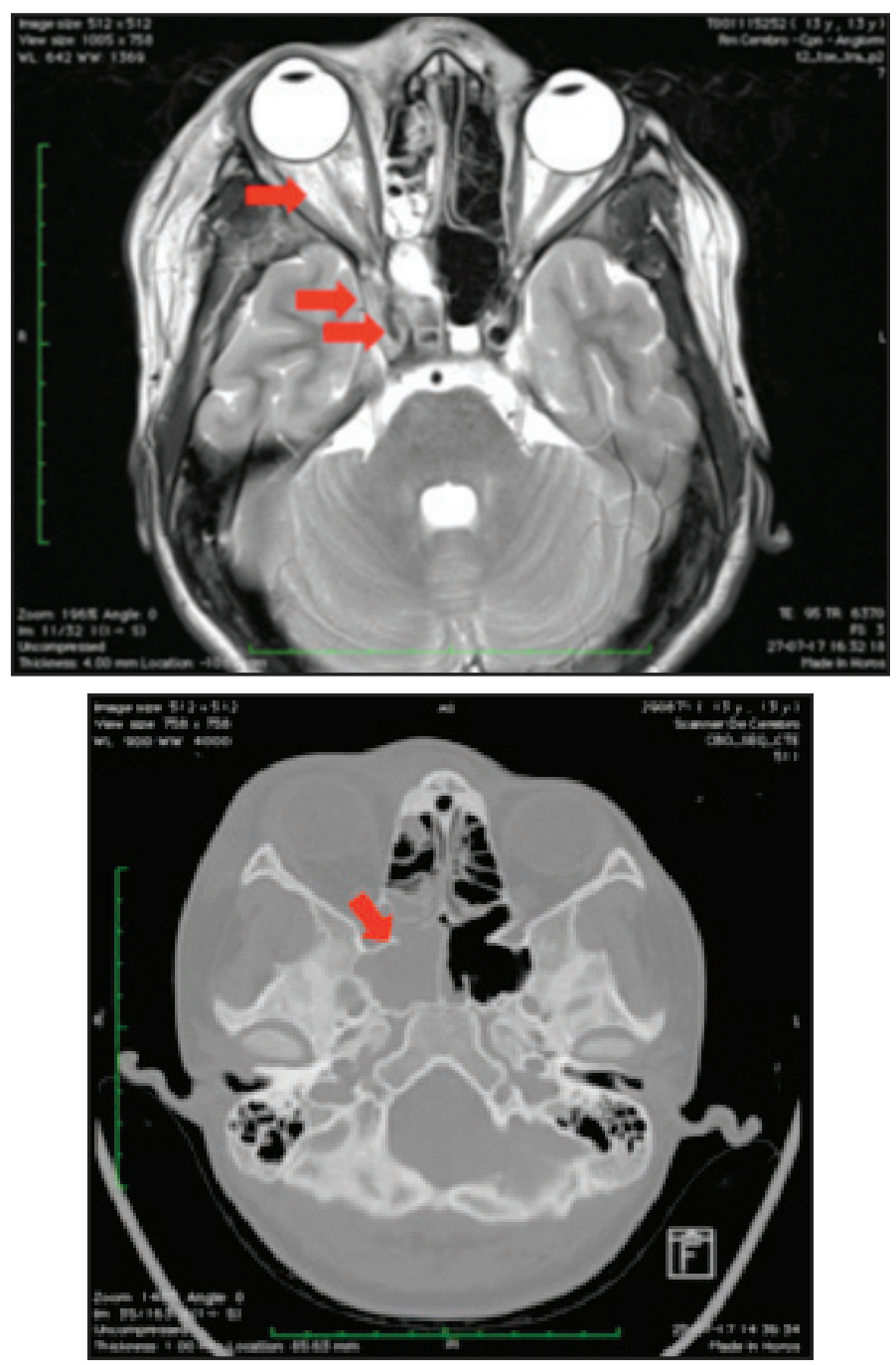

Figura 4. (a) A la izquierda RM de cavidades paranasales, T2, corte axial. De anterior a posterior (flechas) se observa celulitis postseptal, trombosis del seno cavernoso derecho y disminución del calibre del segmento intracavernoso de la carótida interna derecha. (b) a la derecha RM de cavidades paranasales, T2, corte coronal. Se observa la disminución del calibre del segmento intracavernoso de la carótida interna derecha (flecha).

y cols, en su serie de 104 pacientes lo observaron en el $1 \%{ }^{3}$. El mecanismo por el cual se produce la progresión intracraneal es a través de extensión lateral ósea y/o mucosa directa, o por tromboflebitis de las venas emisarias que drenan al seno cavernos $0^{7,10}$. Tradicionalmente, la causa más común de TSC ha sido la infección cutánea de la cara por estafilococos ${ }^{8}$. Sin embargo, se ha informado un aumento de la rinosinusitis como causa $^{10}$. Estudios que revisan la bacteriología de la
RSA esfenoidal ha demostrado que el estreptococo es el organismo más comúnmente asociado, por lo que, si consideramos un diagnóstico de TSC asociada a enfermedad rinosinusal, se debe considerar a los organismos estreptocócicos como el principal agente ${ }^{7,11}$. Lizé y cols, describen que los microorganismos más frecuentemente identificados son especies de Streptococcus (43\%) y Staphylococcus aureus $(29 \%)^{12}$. La rinosinusitis, principalmente esfenoidal y etmoidal, son la princi- 
pal causa de esta enfermedad, y se han identificado como factores de riesgo RSC y diabetes ${ }^{12,13}$. La tasa de mortalidad ha sido reportada entre $14 \%$ $79 \%^{10,12,13}$, sin embargo, se debe tener precaución con estas cifras, ya que muchos de los pacientes fueron tratados hace más de 20-30 años ${ }^{2}$. Los avances en la evaluación radiológica, así como en los tratamientos médicos y quirúrgicos, parecen haber mejorado el pronóstico global de esta complicación ${ }^{9}$. En la era posantibiótico su incidencia ha disminuido drásticamente, pero su mortalidad permanece sobre $30 \%$, por lo que es fundamental diagnosticarla de forma precoz $z^{8,10,14,15}$.

Los síntomas principales que deben alertar al médico son fiebre alta y fluctuante, cefalea frontal y retroorbitaria inusual, que aumenta y persiste, pese al uso de analgésicos, asociado a síntomas oculares como irritación ocular o quemosis, edema preseptal, proptosis, ptosis y oftalmoplejía $2,7,8,10,11$. Los síntomas oculares son signos tempranos de congestión venosa y se observan de forma frecuente, pudiendo incluso ser bilaterales por la tromboflebitis de las venas intercavernosas ${ }^{8,11}$. La TSC debe sospecharse en el contexto de una progresión rápida de los signos clínicos, conciencia alterada 0 restricción de la motilidad ocular fuera de proporción con el grado de proptosis². Lizé y cols, demostraron que la clínica más frecuente fue: cefalea (100\%); daño de pares craneanos (86\%), afectándose los pares III, IV, V2, VI, X y XII; fiebre (71\%); y patología de órbita $(71 \%)$, que incluye: quemosis, proptosis, ptosis y pérdida visual ${ }^{12}$. Esta última puede deberse a ulceración corneal, oclusión de la arteria oftálmica, embolía venosa, isquemia del nervio óptico o a una compresión intraorbitaria, siendo persistente solo en el $8 \%$ a $16 \%$ de los pacientes ${ }^{10}$. También encontraron asociación, de forma menos frecuente a síndrome de Horner en $14 \%$ y síntomas neurológicos en $43 \%$ (rigidez de nuca, alteración de conciencia y convulsiones) ${ }^{12}$.

Actualmente la TC y RM se usan para confirmar la sospecha clínica de trombosis del seno cavernoso $0^{7,16,17}$. Previamente se consideraba a la TC con contraste el examen radiológico de elección para el diagnóstico precoz de TSC, con hallazgos radiológicos que incluyen áreas confluentes de no opacificación en el seno cavernoso, abombamiento convexo de la pared lateral del seno cavernoso, expansión del seno cavernoso y asimetría entre los dos lados del seno cavernoso ${ }^{16}$. Todos hallazgos presentes en nuestro paciente. La RM estaba reservada como un examen de segunda línea, donde lo más típico era observar la pérdida en T1 de la heterogeneidad de la señal, que se reemplaza por una señal T1 homogénea iso 0 hiperintensa ${ }^{16}$. En la actualidad la RM con parámetros de flujo y venografía son más sensibles que la TC para la evaluación de la TSC. En estas modalidades podemos encontrar: deformidad de la porción cavernosa de la arteria carótida, señal heterogénea del seno cavernoso afectado y señal hiperintensa de todos los senos venosos trombosados ${ }^{7,8}$. De las imágenes utilizadas en Lizé y cols, en tres pacientes se usó TC y en cuatro TC y RM. El hallazgo radiológico más frecuente era un defecto de llenado en el seno cavernoso, parcial o completo, presente en el $100 \%$ de los casos, seguido por un desplazamiento lateral de la pared lateral del seno cavernoso, observado en $71 \%$ y expansión global del seno cavernoso observada en $57 \%{ }^{12}$. Otros hallazgos incluyen: expansión de la vena oftálmi$\mathrm{ca}$, trombosis que se extiende al seno cavernoso contralateral y trombosis que se extiende al seno transverso ipsilateral ${ }^{12}$. En la literatura se describen casos bilaterales, pero no son comunes ${ }^{14}$. Entre las complicaciones tardías se describen insuficiencia hipofisaria, trombosis venosa cortical y abscesos epidurales, subdurales o parenquimatosos, además, si existe afectación de la arteria carótida puede conducir a una fístula carótido-cavernosa 0 a un aneurisma carotíde ${ }^{15}$. También se ha descrito el síndrome de Lemierre como resultado de émbolos sépticos ${ }^{7,8}$. En la misma serie mencionada previamente se observó que en $57 \%$ de los casos hubo complicaciones intracraneales, entre las que se encuentran: absceso ponto cerebeloso, absceso extradural frontal, aneurisma micótico de la arteria carótida interna intracavernosa y absceso del pedúnculo cerebeloso medio izquierdo ${ }^{12}$.

El tratamiento de la TSC como complicación de una RSA se basa en una triterapia: antibióticos, drenaje quirúrgico y anticoagulación, siendo los dos primeros tratamientos bien establecidos, mientras que el rol de la anticoagulación es polémico ${ }^{10}$. Lo primero es iniciar un tratamiento empírico con dosis altas de antibióticos endovenosos, que traspasen la barrera hematoencefálica y estén dirigidos contra Staphylococcus aureus, microorganismos gram 
positivos y anaerobios ${ }^{7,12}$. Una opción sería iniciar tratamiento con penicilinas de segunda generación (cloxacilina), ceftriaxona y metronidazol, considerando vancomicina en vez de una penicilina de segunda generación si sospechamos Staphylococcus meticilino resistente ${ }^{7,8,10,14,15}$. Su duración es tema controvertido y depende de los hallazgos microbiológicos y si existe asociación a complicaciones intracraneales, considerando la terapia antifúngica si se detectan hongos en las muestras de mucosa del seno ${ }^{12}$. También se debe realizar un drenaje quirúrgico del seno infectado, idealmente con abordaje endoscópico ${ }^{10,15}$. Lizé y cols, consideran que es un procedimiento efectivo con baja morbilidad y se debe realizar tan pronto como se hace el diagnóstico de TSC, consistiendo en esfenoidectomía y/o etmoidectomía posterior ${ }^{12}$. Con respecto a la terapia anticoagulante, si bien su eficacia es indeterminada y puede causar 0 exacerbar una hemorragia intracraneana concurrente, acorde a una revisión de Bhatia y cols, es infrecuente que genere una hemorragia y sería benéfico si se administra dentro de los 7 primeros días de hospitalización (después de descartar una hemorragia intracraneana con imágenes) disminuyendo la morbilidad y mortalidad en estos pacientes ${ }^{10}$. La terapia anticoagulante consiste en heparina no fraccionada o de bajo peso molecular, seguida por la administración de un antagonista de la vitamina $K$, hasta la recanalización radiológica completa del seno cavernoso, confirmada mediante TC con contraste que se realiza al mes de tratamiento, y cada dos semanas si es necesario ${ }^{12}$.

También se ha considerado el uso de corticoides en estos casos, pero es tema controvertido, ya que puede disminuir la respuesta inmune y potenciar la

\section{BIBLIOGRAFÍA}

1. Meltzer E., Hamilos D., Hadley J., y cols. Rhinosinusitis: Establishing definitions for clinical research and patient care. J. Allergy Clin. Immunol. 2004; 114: 155-212.

2. Carr T. Complications of Sinusitis. Am J Rhinol Allergy. 2016; 30(4): 241-5.

3. OXFoRd L., McClay J. Complications of acute sinusitis in children. Otolaryngol Head Neck Surg. 2005; 133: 32-7. sepsis, por lo que antes de usarlos se debe realizar un análisis costo-beneficio. Este tratamiento solo está indicado cuando se produce hipopituitarismo por isquemia de la glándula $a^{7,15}$. Se describe que la morbilidad de la TSC es alta: 7\%-22\% desarrollaron pérdida de la visión en forma parcial, 8\%-17\% desarrolló ceguera ${ }^{10}$ y hasta $50 \%$ desarrolló déficit en nervios craneanos $^{18}$. Entre las secuelas observadas en Lizé y cols, se describe que hasta $57 \%$ desarrolla déficit neurológico, transitorio o permanente, manifestado por pérdida visual ipsilateral permanente, déficit transitorio de los nervios craneales X y XII, síndrome de Horner asociado a hipoestesia del nervio V2 y la disestesia del nervio V2 ${ }^{12}$. La trombosis infecciosa del seno cavernoso secundaria a sinusitis es una patología rara que permanece desconocida para los médicos generales, por lo tanto, a menudo hay un retraso entre los primeros síntomas de esta patología y el inicio del tratamiento, lo que es potencialmente catastrófico ${ }^{7,12}$.

\section{CONCLUSIÓN}

La TSC es considerada una complicación severa de la RSA. Según la literatura su morbilidad y mortalidad ha disminuido las últimas décadas, pero las secuelas siguen siendo frecuentes. Lo fundamental es realizar un diagnóstico precoz a través de su sospecha clínica, confirmarlo con imágenes como TC o RM, e iniciar un manejo agresivo que combine dosis altas de antibióticos endovenosos, terapia anticoagulante y un drenaje endoscópico precoz, lo que reduce sustancialmente la morbilidad y mortalidad.
4. Martel F., Moreno C., Iñiguez R., Fernández R., Rosenblut A. Complicaciones de rinosinusitis aguda en niños del Hospital Sótero del Río. Rev. Otorrinolaringol. Cir. Cabeza Cuello. 2008; 1: 16-20.

5. Boettiger P., Martelo G., Zúñiga J., Celedón C. Complicación del drenaje endoscópico en un paciente con absceso retroorbitario. Caso clínico. Rev. Otorrinolaringol. Cir. Cabeza Cuello. 2011; 3: 263-6.

6. Chander J., Langenbrunner D., Stevens E. The 
pathogenesis of orbital complications in acute sinusitis. Laryngoscope 1970; 80: 1414-28.

7. Dyer S., Thottam P., Saraiya S., Haupert M. Acute sphenoid sinusitis leading to contralateral cavernous sinus thrombosis: a case report. $J$ Laryngol Otol. 2013; 127: 814-6.

8. Cannon M., Antonio B., McCloskey J., Hines M., ToBin J., Shetty A. Cavernous sinus thrombosis complicating sinusitis. Pediatr Crit Care Med. 2004; 5: 86-8.

9. Bayonne E., Kania R., Tran P., Huy B., Herman P. Intracranial complications of rhinosinusitis. A review, typical imaging data and algorithm of management. Rhinology. 2009; 47: 59-65.

10. Bhatia K., Jones N. Septic cavernous sinus thrombosis secondary to sinusitis: are anticoagulants indicated? A review of the literature. $J$ Laryngol Otol. 2002; 116: 667-76.

11. DiNuBiLE M. Septic thrombosis of the cavernous sinuses. Arch Neurol. 1988; 45: 567-72.

12. Lizé F., Verillaud B., Vironneau P., y cols. Septic cavernous sinus thrombosis secondary to acute bacterial sinusitis: A retrospective study of seven cases. Am J Rhinol Allergy. 2015; 29: 7-12.
13. Chen H-W., Su C-P., Su D-H., Chen H-W., Chen Y-C. Septic cavernous sinus thrombosis: an unusual and fatal disease. J Formos Med Assoc. 2006; 105: 203-9.

14. Eweiss A., Mukonoweshuro W., Khalil HS. Cavernous sinus thrombosis secondary to contralateral sphenoid sinusitis: a diagnostic challenge. J Laryngol Otol. 2010; 124: 92830.

15. Younis R., Lazar R. Cavernous sinus thrombosis: successful treatment using functional endonasal sinus surgery. Arch Otolaryngol Head Neck Surg. 1993; 119: 1368-72.

16. Schuknecht B., Simmen D., Yürsel C., Valavanis A. Tributary venosinus occlusion and septic cavernous sinus thrombosis: CT and MR findings. Am J Neuroradiol. 1998; 19: 617-26.

17. Dankbaar JW., Van Bemmel AJ., Pameijer Fa. Imaging findings of the orbital and intracranial complications of acute bacterial rhinosinusitis. Insights Imaging. 2015; 6: 509-18.

18. Miller C., Suh J., Henriquez 0., Schlosser R., Ramakrishnan V., Chiu A. Prognosis for sixth nerve palsy arising from paranasal sinus disease. $A m$ J Rhinol Allergy. 2013; 27: 432-5.

Correspondencia: Constanza Valdés $P$.

Av. Salvador \#486. Providencia. Santiago, Chile E mail: cvaldesp@clc.cl 